\title{
Is it the right time for an infant screening for Duchenne muscular dystrophy?
}

\author{
Gian Luca Vita ${ }^{1} \cdot$ Giuseppe Vita $^{1,2}$ (D) \\ Received: 18 November 2019 / Accepted: 20 February 2020 / Published online: 28 February 2020 \\ (C) The Author(s) 2020
}

\begin{abstract}
Newborn screening (NBS) is an essential, preventive public health programme for early identification of disorders whose early treatment can lead to significant reduction in morbidity and mortality. NBS for Duchenne muscular dystrophy (DMD) has been a controversial matter for many years, because of false positives, the lack of effective drugs and the need of more data about screening efficacy. The still high diagnostic delay of DMD and the current availability of drugs such as steroid, ataluren, eteplirsen, golodirsen and forthcoming new drugs, improving the clinical conditions if early started, make appropriate to begin a concrete discussion between stakeholders to identify best practice for DMD screening. A two-step system CK/DNA screening programme is presented to be performed in male infants aged between 6 months and 42 months involving more than 30,000 male infants. Five to eight DMD subjects are believed to be diagnosed. The pilot project would give the opportunity to test in a small population the feasibility of an infant screening programme, which in the near future could be applicable to an entire country.
\end{abstract}

Keywords Duchenne muscular dystrophy $\cdot$ Early diagnosis $\cdot$ Infant screening $\cdot$ Public health

\section{Background}

Newborn screening (NBS) is internationally recognised as an essential, preventive public health programme for early identification of disorders in newborns that can affect their longterm health. Early detection, diagnosis and treatment can lead to significant reduction in morbidity and mortality and may facilitate informed decision-making for future pregnancies. So far, NBS has been implemented only in very few neuromuscular diseases. Medium-chain acyl-CoA dehydrogenase deficiency, the most common inherited defect of mitochondrial fatty acid oxidation, was included in NBS programmes of many countries since the late 1990s. Measured concentration of acylcarnitines is parameter on which to base a follow-up testing for definitive diagnosis and consequent early treatment including the advice to avoid prolonged fasting and an emergency regimen during intercurrent illness [1]. After

Giuseppe Vita

vitag@unime.it

1 Nemo Sud Clinical Centre for Neuromuscular Disorders, Messina, Italy

2 Unit of Neurology and Neuromuscular Diseases, Department of Clinical and Experimental Medicine, University of Messina, Messina, Italy introduction of enzyme replacement therapy (ERT) with recombinant human alpha-glucosidase, the first NBS programme for Pompe disease began in Taiwan in 2005 and was then definitely incorporated into the national system in 2008 [2]. Despite some controversies including that (i) most individuals can remain asymptomatic for years or decades and (ii) there is no consensus on when to begin ERT for those with non-infantile forms, some US states began NBS for Pompe disease [3].

The therapeutic scenario of spinal muscular atrophy (SMA) has been recently subverted by introduction of nusinersen [4]. Despite the high cost and different refund policies of health insurances in different countries, its availability is increasing worldwide. Moreover, US Food and Drug Administration (FDA) has just approved SMN1 gene replacement and granted priority review for risdiplam, another SMN2 splicing modifier [4], reinforcing the commitment of health authorities, pharmaceutical companies and advocacy groups to guarantee equity and access to treatment to all patients. The results of clinical trials and real-world evidences support the view that the earlier the treatment is started, the better is the efficacy [5-7]. Nurture trial of nusinersen in pre-symptomatic infants is still ongoing, but positive interim analysis confirms that early diagnosis and treatment have the potential to completely change SMA course. There is at the moment a pressing demand for pilot NBS studies to test the possibility to include 
SMA NBS in the public health programmes, an ethically and medically obvious target. Pilot NBS experiences of genetic analysis on dried blood spot (DBS) samples have been conducted in Taiwan [8], New York State [9], and Southern Belgium [10], and one is just started in the Italian regions of Tuscany and Lazio.

\section{Diagnosis and treatment of Duchenne muscular dystrophy}

Duchenne muscular dystrophy (DMD) is an X-linked muscle wasting disorder, leading to wheelchair confinement at 812 years and development of an associated cardiomyopathy, with an incidence of 1:3600-9300 live male births per year [11]. The onset of muscle weakness is typically in early childhood. Without intervention, few patients survived beyond the second decade of life in the past, but nowadays, improved care, in particular cardiac and ventilatory management, has dramatically increased life expectancy [12-15]. Despite advances in technology and increased availability of genetic testing, the mean age at diagnosis is reported to be around the age of 3.5-5 years with a delay of up to 2 years between the appearance of first symptoms and the diagnosis. The incidental finding of increased creatine kinase (CK) serum levels, a biomarker of membrane fragility and muscle degeneration, may represent the most frequent finding leading to a suspicion of DMD (up to 53\% of cases) [16]. In some hospitals or in some countries, $\mathrm{CK}$ is measured as a routine blood test or for pre-anaesthesiologic evaluation [17]. Late diagnosis of DMD may cause inappropriate delayed access to optimal Standards of Care (SOC) [18], including steroids, whose benefit is higher if boys are treated earlier [19]. The FDA has also granted full approval for deflazacort in 2017, making it the first glucocorticoid with a labelled indication specifically for DMD. Moreover, a diagnostic odyssey with prolonged and multiple medical evaluations is in itself distressing, is often expensive and prevents parents from accessing genetic counselling and future prenatal diagnosis.

In 2014, the European Medicines Agency (EMA) gave to ataluren a conditional approval for the treatment of ambulatory DMD patients aged 5 years and older with nonsense mutation. Point mutations introducing a premature stop codon into mRNA and therefore causing the translation of a truncated and non-functional dystrophin protein are present in $10-15 \%$ of DMD patients [20]. In a few years, ataluren became available as the first approved drug for DMD in more than 25 countries but not in USA. In October 2018, PTC Therapeutics announced preliminary data from the first international drug registry for DMD patients receiving ataluren (Translarna ${ }^{\mathrm{TM}}$ ), highlighting the long-term clinical benefit in delaying irreversible muscle loss when compared with published natural history. In the real-world setting, DMD children and adolescents are continuing to walk years longer than untreated children and are staying more physically able. A time-to-event analysis for loss of ambulation in treated subjects has shown a median age of loss of ambulation of 16.5 years of age (https://www. multivu.com/players/English/8420051-ptc-therapeuticsstride-registry-duchenne-muscular-dystrophy-translarna). Based on the positive results of a phase 2 study in DMD children from 2 to 5 years, in July 2018, EMA has extended the indication of ataluren since the age of 2 years.

Many companies are developing a variety of other drugs for DMD, based on exon-skipping technology and other mechanisms of action [4]. Eteplirsen, commercially available as Exondys $51^{\mathrm{TM}}$ in the USA, obtained in September 2016 a conditional approval by FDA to treat DMD patients amenable to exon 51 skipping (approx. 13\% of DMD patients) [21]. In December 2019, FDA approved also golodirsen (Vyondys $53^{\mathrm{TM}}$ ) to treat DMD patients with a confirmed mutation amenable to exon 53 skipping (approx. 8\% of DMD community).

\section{Lessons from previous experiences of NBS in DMD}

The 195th ENMC International workshop on newborn screening for DMD, held in 2012 to discuss pros and cons of an NBS programme to anticipate diagnosis, led to a wait-and-see position, despite the notion that physiotherapy and steroid treatment could be implemented earlier as a result of NBS. The reasons were the lack of effective drugs despite ongoing experimental trials at that time, the belief that NBS programme should be introduced as voluntary screening whose details should be yet evaluated and discussed, and the need to have more data about screening efficacy [22]. At that workshop, the results of a recently published two-tiered CK/DNA NBS approach were presented and discussed [23]. It consisted of i) a DBS CK test in newborn male infants at major birthing hospitals of Columbus and Cincinnati, Ohio, USA after parents' informed consent; ii) a second CK test by venous blood sample in those resulted with $\mathrm{CK} \geq 600 \mathrm{U} / \mathrm{l}$; and iii) DNA screening on DBS in those males with $\mathrm{CK} \geq 750 \mathrm{U} / 1$. Lessons learnt were that increased CK level were found in newborns, not confirmed by a second CK test, most likely because of the muscle trauma during progression through the birth canal, and that $308 / 37,649$ had CK levels $>750 \mathrm{U} / 1$ but only 10 had $\mathrm{CK} \geq 2000 \mathrm{U} / 1$. Six males were found to have $D M D$ gene mutations, all deletions, 5 out-of-frame and 1 in-frame. All samples with $D M D$ mutations had CK values $\geq 2000 \mathrm{U} / \mathrm{l}$. In the subjects with $C K \geq 2000 \mathrm{U} / 1$ without $D M D$ mutations, the most common limb-girdle muscular dystrophy (LGMD) genes were investigated and mutations in DYSF, SGCB and FKRP genes were found.

Further interesting results were reported in a study describing 21-year experience of DMD NBS in Wales, UK [24]. The 
lowest serum CK activity in the boys with confirmed DMD diagnosis was $2442 \mathrm{U} / 1$ when measured at the 6- to 8-week follow-up appointment after NBS. Surprisingly, over the 21year period, 343,025 boys resulted with a CK level $<250 \mathrm{U} / 1$ at 5-8 days of life, but 13 were then found to be false-negative. They were diagnosed to have DMD after a level of CK between 6000 and 37,296 U/1 was found at the age of 1.47.85 years. The authors explained that the false-negative cases simply be due to the insensitivity of the analytical test utilised to screen those samples collected at days 5 to 8 of life.

Recently, the enthusiasm for early DMD diagnosis by NBS increased amongst clinicians and patient associations. Pilot NBS studies have been performed in the Zhejiang Province in China and in Australia, where it is looking for the optimal time, comparing $24-96 \mathrm{~h}$ vs $6-7$ days vs $6-$ 12 weeks of age [25]. In EU, the general situation of NBS varies a lot, from 5 diseases in France to 9 in UK and 14 in Germany. The most advanced countries are Sweden, Finland, Hungary and Poland, where a range from 22 to 26 diseases are compulsorily screened at birth. Italy profiles itself as a leader amongst European countries with more than 40 diseases, although not all adopted in all regions. No country yet includes DMD.

DMD patients and their parents are strongly in favour of NBS, regardless of whether their diagnosis was made shortly after birth by NBS or after symptom onset. Boys diagnosed by NBS and their parents reported a positive impact of NBS on their quality of life. Expectations are high, and no negative psycho-social impacts of NBS were identified amongst those families who received a diagnosis through NBS [26, 27].

\section{A proposal of infant screening for DMD}

The current availability of drugs such as steroid, ataluren, eteplirsen, golodirsen and forthcoming new drugs, improving the clinical conditions if early started, and the still high diagnostic delay, make appropriate to begin a concrete discussion between DMD experts and advocacy groups to implement pilot screening projects to have additional experience and to identify best practice for DMD screening. A pilot project would give the opportunity to test in a small population the feasibility of a screening programme, which in the near future could be applicable to an entire country. A good screening blood test must be simple to perform, effective, cheap and patient-friendly.

The present two-step system proposal has been selected to receive funding by PTC Innovative Research Funding programme PRIORITY, a 2019 global programme designed with the aim to improve rates of DMD screening in infants and facilitate earlier diagnosis.

\section{Population}

Previous NBS experiences in DMD identified the age older than 2 months as appropriate to avoid false-positive results of increased CK, due to muscle trauma at birth, and to prevent unnecessary family distress. Moreover, DMD screening resulted to be feasible in the paediatric office, during a routine visit, and it has the advantage to give more time to the parents to understand the risks and benefits of DMD screening in a less frantic environment comparing with newborn period [28].

Consequently, DBS will be performed in infants aged at least 6 months. The screening programme will be communicated to the parents during a routine well-child visit by the Italian National Health Service (NHS) family paediatrician. In the provinces of Messina and Catania, Italy, we expect to have approx. 6500 male births/year. According to DMD incidence and since age of symptom onset is mostly between 30 and 42 months, we plan to screen male infants aged between 6 months and 42 months in a 1.5 -year period, so a total of more than 30,000 male infants. We expect to find 5-8 DMD subjects. We want to limit the pilot screening study to a relatively small number of participants to be able to test the project and to identify more easily critical issues and areas for improvement. The project has been approved by the local ethics committee. Since we offer to the families the right to have a choice, a signed parental consent is mandatory.

\section{Information brochure}

Parents frequently do not fully understand the implications of being included in an NBS programme. Moreover, in some countries and even in different areas of the same country, several factors such as culture, society, history and religion may influence the opinion of the wider public towards genetic issues. Although diminishing, a discrimination against people with hereditary diseases and disability globally may still exist, so that having a hereditary disease is felt and recognised as a "family's shame". In this case, improvement of genetic education and tools for coping with diagnosis may be obtained by adequate information with brochure and families' participation [17]. For these reasons, a brochure will be prepared together with DMD advocacy groups, describing the disease, its management, how the screening programme will identify infants likely to have DMD or other non-DMD muscle diseases, and its benefits and risks. To allow time for the parents to consider the decision fully and make a reasoned choice, DBS can be collected at the following visit.

\section{Training, sampling and laboratory methods}

Approx. 210 NHS paediatricians, operating in the territory, will participate to the project. They will be visited and trained by nurses involved in the screening programme, to perform blood 
sampling technique. Small volume of whole blood is collected from a finger, toe or heel prick with the aid of sterile disposable lancet and spotted onto filter paper. DBS cards are then dried at room temperature for $2-3 \mathrm{~h}$ in a suitable setting, properly stored and then shipped to analytical laboratory through mail or courier. Before starting the project, experiments will be done to measure long-term stability of $\mathrm{CK}$ at room temperature to find the best way of storage and to minimise analyte degradation [29]. The blood spot cards also include demographic information and date and time of collection.

Dried blood spots are punched using a DBS puncher and then processed to measure $\mathrm{CK}$ by liquid chromatography mass spectroscopy (LC-MS). LC-MS is a cheap, confident and user-friendly method, widely implemented in paediatric settings and associated to newborn screening programmes, as a part of public health policies [30]. Preliminarily, samples from unaffected, healthy infants will be tested for assay development and validation.

\section{Follow-up at neuromuscular centre}

In one NBS programme, boys with CK levels $\geq 750 \mathrm{U} / 1$ represented $0.8 \%$ of the total screened cohort, and in another, approximately $50 \%$ of the screen positives (CK $\geq 200 \mathrm{U} / \mathrm{l})$ were transient when repeated at triplicate. However, all boys with confirmed $D M D$ mutation had CK levels $\geq 2000 \mathrm{U} / 1$ [23, $24,31]$. Therefore, the threshold for DNA testing can be increased, improving the potential cost-benefit ratio, and the following steps are suggested in our proposal:

- Blood samples with CK levels $\geq 1000 \mathrm{U} / 1$ are tested for DNA analysis. The multiplex ligation-dependent probe amplification (MLPA) technique will be performed as first approach to detect deletions and duplications in all 79 exons of the dystrophin gene. Since $30 \%$ of patients have small mutations which are not detected by MLPA, further analysis will be performed by using the Sanger method/next generation sequencing. In the case of negative results, a next generation sequencing approach will be used by a panel analysis for the screening of other known genes [32, 33]. Communication of DMD or other non-DMD muscle diseases diagnosis will be approached with genetic counselling and providing adequate psychological support. If no gene mutation is confirmed, boys are followed at the neuromuscular centre according to current clinical practice for asymptomatic hyperCKemia [34, 35];

- If CK levels $<1000$ but $\geq 250 \mathrm{U} / 1$, parents are asked to allow a retest. If elevated $\mathrm{CK}$ is confirmed, above cited guidelines for asymptomatic hyperCKemia will be followed.

Infant screening for hyperCKemia will offer the opportunity to identify not only boys with DMD but also some boys with Becker muscular dystrophy (BMD) and other early-onset treatable myopathies such as Pompe disease [2, 3]. Moreover, identification of DMD/BMD patients will allow to detect also the respective female carriers of their families, allowing a conscious family planning and/or a prenatal diagnosis.

\section{Discussion}

In 2014, ataluren became the first approved drug for DMD patients aged $\geq 5$ years with nonsense mutation, and in 2018, EMA has extended its indication since the age of 2 years. Many companies are developing a variety of other drugs for DMD patients, based on exon-skipping technology and other mechanisms of action. The identification of therapeutic interventions that are more effective as early started and even more in the pre- symptomatic stage has created a pressing demand for NBS studies, in order to detect and start to treat asymfvptomatic individuals and provide the opportunity to slow down disease progression and to reduce morbidity and mortality.

The here present project wants to be a pilot experience about infant screening for DMD to be performed in a territory with approx. 1.7 million inhabitants. It is a feasibility study on a small cohort of subjects to verify different issues. First of all, the problem of false-positive results of increased $\mathrm{CK}$ which can be observed in the newborn population is solved by starting DBS at 6 months of age. Consequently, DBS is collected on filter paper by the NHS paediatricians after signed parental consent. Then, the laboratory test is performed at our tertiary neuromuscular centre by using LC-MS. The positive subjects will be invited to a visit at our centre to verify the provisional diagnosis of DMD or other muscle disease and genetic analysis and/or muscle biopsy will be done for confirmation. This will offer the opportunity to diagnose also other muscle disorders with early hyperCKemia. In that event, we have to consider that some of them are treatable such as Pompe disease, but others are untreatable, with early or even later clinical onset. In such cases, genetic counselling, psychological support and follow-up will be offered [36]. On the other hand, we are also conscious that subjects with $D M D$ gene mutation-related cardiomyopathy have normal or near normal $\mathrm{CK}$, so that they cannot be identified by this programme. The results of the present screening programme will also allow to evaluate its economic sustainability and the sensibility of CK assay in our population, to better plan future national screening.

The primary goals of early DMD diagnosis are in the best interest of the child and his family, such as to start early intervention and to prevent distressing diagnostic odyssey. Secondary benefits are to provide a prompt family's genetic counselling, with additional psychological support, to identify DMD carriers and to offer reproductive risk and prenatal 
diagnosis. Apart from steroid and SOC, early diagnosis would also allow to approach the neurodevelopmental difficulties that are often present in very young DMD boys [37], as well exercise regimes, gradually introduced, to keep muscles supple and prevent or minimise tightness at the joints.

Amongst ongoing DMD clinical trials with innovative medicines, some are based on exon-skipping antisense oligonucleotides (ASO) technology, and at least three are investigating the approach of systemic gene therapy using a micro-dystrophin gene, and in one of them, the age eligible for the study starts at 3 months of age [4]. Dystrophic pathology has been described in DMD foetuses [38], and early pelvic girdle musculature involvement can be identified by magnetic resonance in the first 2 years of life in DMD boys [39]. The therapeutic benefit of early beginning of steroid treatment could be the result of having higher amount of muscle tissue responsive to treatment and lesser fibrosis [19]. This has been supported also with the innovative therapy eteplirsen [40]. Indeed, all these evidences represent the essential prerequisite to implement a specific population screening for early DMD diagnosis.

A very recent evidence-based consensus and systematic review on measures to reduce the time to DMD diagnosis investigated also the attitude of fifteen experts if NBS should be performed. A total of $47 \%$ answered "yes", $47 \%$ answered "not sure", and one answered "no". The reason for $47 \%$ answering "not sure" was mainly related to the absence of available treatments for patients younger than 5 years of age (at the time of investigation ataluren has not been yet approved for children as young as 2 years). Moreover, $75 \%$ believed that CK-based NBS would improve standards of care and family planning [41]. NBS has been discussed for many years, but now, with promising treatments already available or on the horizon, it became an even more appropriate matter. We believe that enough reasons support the implementation of NBS programmes for DMD to avoid delays in initiating beneficial treatments.

Funding information This pilot study is supported by PTC Therapeutics International Limited through the PRIORITY programme - PTC Innovative Research Funding programme.

\section{Compliance with ethical standards}

Conflict of interest GLV is sub-investigator and GV is principal investigator in clinical trials in Duchenne muscular dystrophy sponsored by Italfarmaco, PTC, Roche, Santhera, Sarepta and Wave.

Ethical approval All procedures described in this pilot screening programme are in accordance with the ethical standards of the institutional and national research committee. The study has been approved by the local ethics committee. A signed parental consent is mandatory.

Open Access This article is licensed under a Creative Commons Attribution 4.0 International License, which permits use, sharing, adaptation, distribution and reproduction in any medium or format, as long as you give appropriate credit to the original author(s) and the source, provide a link to the Creative Commons licence, and indicate if changes were made. The images or other third party material in this article are included in the article's Creative Commons licence, unless indicated otherwise in a credit line to the material. If material is not included in the article's Creative Commons licence and your intended use is not permitted by statutory regulation or exceeds the permitted use, you will need to obtain permission directly from the copyright holder. To view a copy of this licence, visit http://creativecommons.org/licenses/by/4.0/.

\section{References}

1. Jager EA, Kuijpers MM, Bosch AM, Mulder MF, Gozalbo ER, Visser G, de Vries M, Williams M, Waterham HR, van Spronsen FJ, Schielen PCJI, Derks TGJ (2019) A nationwide retrospective observational study of population newborn screening for mediumchain acyl-CoA dehydrogenase (MCAD) deficiency in the Netherlands. J Inherit Metab Dis 42:890-897

2. Yang CF, Liu HC, Hsu TR, Tsai FC, Chiang SF, Chiang CC, Ho HC, Lai CJ, Yang TF, Chuang SY, Lin CY, Niu DM (2014) A largescale nationwide newborn screening program for Pompe disease in Taiwan: towards effective diagnosis and treatment. Am J Med Genet A 164A:54-61

3. Ross LF, Clarke AJ (2017) A historical and current review of newborn screening for neuromuscular disorders from around the world: lessons for the United States. Pediatr Neurol 77:12-22

4. Vita G, Vita GL, Musumeci O, Rodolico C, Messina S (2019) Genetic neuromuscular disorders: living the era of a therapeutic revolution. Part 2: diseases of motor neuron and skeletal muscle. Neurol Sci 40:671-681

5. Finkel RS, Mercuri E, Darras BT, Connolly AM, Kuntz NL, Kirschner J, Chiriboga CA, Saito K, Servais L, Tizzano E, Topaloglu H, Tulinius M, Montes J, Glanzman AM, Bishop K, Zhong ZJ, Gheuens S, Bennett CF, Schneider E, Farwell W, De Vivo DC, ENDEAR Study Group (2017) Nusinersen versus sham control in infantile-onset spinal muscular atrophy. N Engl J Med 377:1723-1732

6. Mendell JR, Al-Zaidy S, Shell R, Arnold WD, Rodino-Klapac LR, Prior TW, Lowes L, Alfano L, Berry K, Church K, Kissel JT, Nagendran S, L'Italien J, Sproule DM, Wells C, Cardenas JA, Heitzer MD, Kaspar A, Corcoran S, Braun L, Likhite S, Miranda C, Meyer K, Foust KD, Burghes AHM, Kaspar BK (2017) Singledose gene-replacement therapy for spinal muscular atrophy. N Engl J Med 377:1713-1722

7. Pane M, Coratti G, Sansone VA, Messina S, Bruno C, Catteruccia M, Sframeli M, Albamonte E, Pedemonte M, D'Amico A, Bravetti C, Berti B, Brigati G, Tacchetti P, Salmin F, de Sanctis R, Lucibello S, Piastra M, Genovese O, Bertini E, Vita G, Tiziano FD, Mercuri E, Italian Expanded Access Program Working Group (2019) Nusinersen in type 1 spinal muscular atrophy: twelve-month realworld data. Ann Neurol 86:443-451

8. Chien YH, Chiang SC, Weng WC, Lee NC, Lin CJ, Hsieh WS, Lee WT, Jong YJ, Ko TM, Hwu WL (2017) Presymptomatic diagnosis of spinal muscular atrophy through newborn screening. J Pediatr 190:124-129

9. Kraszewski JN, Kay DM, Stevens CF, Koval C, Haser B, Ortiz V, Albertorio A, Cohen LL, Jain R, Andrew SP, Young SD, LaMarca NM, De Vivo DC, Caggana M, Chung WK (2018) Pilot study of population-based newborn screening for spinal muscular atrophy in New York state. Genet Med 20:608-613

10. Boemer F, Caberg JH, Dideberg V, Dardenne D, Bours V, Hiligsmann M, Dangouloff T, Servais L (2019) Newborn screening for SMA in southern Belgium. Neuromuscul Disord 29:343-349

11. Mah JK, Korngut L, Dykeman J, Day L, Pringsheim T, Jette N (2014) A systematic review and meta-analysis on the epidemiology of Duchenne and Becker muscular dystrophy. Neuromuscul Disord 24:482-491 
12. Eagle M, Baudouin SV, Chandler C, Giddings DR, Bullock R, Bushby K (2002) Survival in Duchenne muscular dystrophy: improvements in life expectancy since 1967 and the impact of home nocturnal ventilation. Neuromuscul Disord 12:926-929

13. Ishikawa $Y$, Miura $T$, Ishikawa $Y$, Aoyagi T, Ogata H, Hamada S, Minami R (2011) Duchenne muscular dystrophy: survival by cardio-respiratory interventions. Neuromuscul Disord 21:47-51

14. Birnkrant DJ, Ararat E, Mhanna MJ (2016) Cardiac phenotype determines survival in Duchenne muscular dystrophy. Pediatr Pulmonol 51:70-76

15. Birnkrant DJ, Bushby K, Bann CM, Alman BA, Apkon SD, Blackwell A, Case LE, Cripe L, Hadjiyannakis S, Olson AK, Sheehan DW, Bolen J, Weber DR, Ward LM, DMD Care Considerations Working Group (2018) Diagnosis and management of Duchenne muscular dystrophy, part 2: respiratory, cardiac, bone health, and orthopaedic management. Lancet Neurol 17:347-361

16. D'Amico A, Catteruccia M, Baranello G, Politano L, Govoni A, Previtali SC, Pane M, D'Angelo MG, Bruno C, Messina S, Ricci F, Pegoraro E, Pini A, Berardinelli A, Gorni K, Battini R, Vita G, Trucco F, Scutifero M, Petillo R, D'Ambrosio P, Ardissone A, Pasanisi B, Vita G, Mongini T, Moggio M, Comi GP, Mercuri E, Bertini E (2017) Diagnosis of Duchenne muscular dystrophy in Italy in the last decade: critical issues and areas for improvements. Neuromuscul Disord 27:447-451

17. Takeuchi F, Komaki H, Yamagata Z, Maruo K, Rodger S, Kirschner J, Kubota T, Kimura E, Takeda S, Gramsch K, Vry J, Bushby K, Lochmüller H, Wada K, Nakamura H (2017) A comparative study of care practices for young boys with Duchenne muscular dystrophy between Japan and European countries: implications of early diagnosis. Neuromuscul Disord 27:894-904

18. Messina S, Vita GL (2018) Clinical management of Duchenne muscular dystrophy: the state of the art. Neurol Sci 39:1837-1845

19. Merlini L, Gennari M, Malaspina E, Cecconi I, Armaroli A, Gnudi S, Talim B, Ferlini A, Cicognani A, Franzoni E (2012) Early corticosteroid treatment in 4 Duchenne muscular dystrophy patients: 14year follow-up. Muscle Nerve 45:796-802

20. Mah JK (2018) An overview of recent therapeutics advances for Duchenne muscular dystrophy. Methods Mol Biol 1687:3-17

21. Alfano LN, Charleston JS, Connolly AM, Cripe L, Donoghue C, Dracker R, Dworzak J, Eliopoulos H, Frank DE, Lewis S, Lucas K, Lynch J, Milici AJ, Flynt A, Naughton E, Rodino-Klapac LR, Sahenk Z, Schnell FJ, Young GD, Mendell JR, Lowes LP (2019) Long-term treatment with eteplirsen in nonambulatory patients with Duchenne muscular dystrophy. Medicine (Baltimore) 98(26): e15858

22. Ellis JA, Vroom E, Muntoni F (2013) 195th ENMC international workshop: newborn screening for Duchenne muscular dystrophy 14-16th December, 2012, Naarden, The Netherlands. Neuromuscul Disord 23:682-689

23. Mendell JR, Shilling C, Leslie ND, Flanigan KM, Al-dahhak R, Gastier-Foster J, Kneile K, Dunn DM, Duval B, Aoyagi A, Hamil C, Mahmoud M, Roush K, Bird L, Rankin C, Lilly H, Street N, Chandrasekar R, Weiss RB (2012) Evidence-based path to newborn screening for Duchenne muscular dystrophy. Ann Neurol 71:304 313

24. Moat SJ, Bradley DM, Salmon R, Clarke A, Hartley L (2013) Newborn bloodspot screening for Duchenne muscular dystrophy: 21 years experience in Wales (UK). Eur J Hum Genet 21:10491053

25. Ke Q, Zhao ZY, Griggs R, Wiley V, Connolly A, Kwon J, Qi M, Sheehan D, Ciafaloni E, Howell RR, Furu P, Sazani P, Narayana A, Gatheridge M (2017) Newborn screening for Duchenne muscular dystrophy in China: follow-up diagnosis and subsequent treatment. World J Pediatr 13:197-201

26. Wood MF, Hughes SC, Hache LP, Naylor EW, Abdel-Hamid HZ, Barmada MM, Dobrowolski SF, Stickler DE, Clemens PR (2014) Parental attitudes toward newborn screening for Duchenne/Becker muscular dystrophy and spinal muscular atrophy. Muscle Nerve 49: $822-828$

27. Chung J, Smith AL, Hughes SC, Niizawa G, Abdel-Hamid HZ, Naylor EW, Hughes T, Clemens PR (2016) Twenty-year followup of newborn screening for patients with muscular dystrophy. Muscle Nerve 53:570-578

28. Cyrus A, Street N, Quary S, Kable J, Kenneson A, Fernhoff P (2012) Clinic-based infant screening for Duchenne muscular dystrophy: a feasibility study. PLoS Curr 2:e4f99c5654147a

29. Sharma A, Jaiswal S, Shukla M, Lal J (2014) Dried blood spots: concepts, present status, and future perspectives in bioanalysis. Drug Test Anal 6:399-414

30. Wagner M, Tonoli D, Varesio E, Hopfgartner G (2016) The use of mass spectrometry to analyze dried blood spots. Mass Spectrom Rev 35:361-438

31. Kwon JM, Abdel-Hamid HZ, Al-Zaidy SA, Mendell JR, Kennedy A, Kinnett K, Cwik VA, Street N, Bolen J, Day JW, Connolly AM (2016) Clinical follow-up for Duchenne muscular dystrophy newborn screening: a proposal. Muscle Nerve 54:186-191

32. Ankala A, da Silva C, Gualandi F, Ferlini A, Bean LJ, Collins C, Tanner AK, Hegde MR (2015) A comprehensive genomic approach for neuromuscular diseases gives a high diagnostic yield. Ann Neurol 77:206-214

33. Savarese M, Di Fruscio G, Torella A, Fiorillo C, Magri F, Fanin M, Ruggiero L, Ricci G, Astrea G, Passamano L, Ruggieri A, Ronchi D, Tasca G, D'Amico A, Janssens S, Farina O, Mutarelli M, Marwah VS, Garofalo A, Giugliano T, Sampaolo S, Del Vecchio BF, Esposito G, Piluso G, D'Ambrosio P, Petillo R, Musumeci O, Rodolico C, Messina S, Evilä A, Hackman P, Filosto M, Di Iorio G, Siciliano G, Mora M, Maggi L, Minetti C, Sacconi S, Santoro L, Claes K, Vercelli L, Mongini T, Ricci E, Gualandi F, Tupler R, De Bleecker J, Udd B, Toscano A, Moggio M, Pegoraro E, Bertini E, Mercuri E, Angelini C, Santorelli FM, Politano L, Bruno C, Comi GP, Nigro V (2016) The genetic basis of undiagnosed muscular dystrophies and myopathies: results from 504 patients. Neurology 87:71-76

34. Morandi L, Angelini C, Prelle A, Pini A, Grassi B, Bernardi G, Politano L, Bruno C, De Grandis D, Cudia P, Citterio A (2006) High plasma creatine kinase: review of the literature and proposal for a diagnostic algorithm. Neurol Sci 27:303-311

35. Kyriakides T, Angelini C, Schaefer J, Sacconi S, Siciliano G, Vilchez JJ, Hilton-Jones D, European Federation of Neurological Societies (2010) EFNS guidelines on the diagnostic approach to pauci- or asymptomatic hyperCKemia. Eur J Neurol 17:767-773

36. Zatz M, Passos-Bueno MR, Vainzof M (2016) Neuromuscular disorders: genes, genetic counseling and therapeutic trials. Genet Mol Biol 39:339-348

37. Chieffo D, Brogna C, Berardinelli A, D'Angelo G, Mallardi M, D'Amico A, Alfieri P, Mercuri E, Pane M (2015) Early neurodevelopmental findings predict school age cognitive abilities in Duchenne muscular dystrophy: a longitudinal study. PLoS One 10:e0133214

38. Emery AE (1977) Muscle histology and creatine kinase levels in the foetus in Duchenne muscular dystrophy. Nature 266:472-473

39. Li W, Zheng Y, Zhang W, Wang Z, Xiao J, Yuan Y (2015) Progression and variation of fatty infiltration of the thigh muscles in Duchenne muscular dystrophy, a muscle magnetic resonance imaging study. Neuromuscul Disord 25:373-380 
40. Mendell JR, Rodino-Klapac LR, Sahenk Z, Roush K, Bird L, Lowes LP, Alfano L, Gomez AM, Lewis S, Kota J, Malik V, Shontz K, Walker CM, Flanigan KM, Corridore M, Kean JR, Allen HD, Shilling C, Melia KR, Sazani P, Saoud JB, Kaye EM, Eteplirsen Study Group (2013) Eteplirsen for the treatment of Duchenne muscular dystrophy. Ann Neurol 74:637-647

41. Aartsma-Rus A, Hegde M, Ben-Omran T, Buccella F, Ferlini A, Gallano P, Howell RR, Leturcq F, Martin AS, Potulska-Chromik A,
Saute JA, Schmidt WM, Sejersen T, Tuffery-Giraud S, Uyguner ZO, Witcomb LA, Yau S, Nelson SF (2019) Evidence-based consensus and systematic review on reducing the time to diagnosis of Duchenne muscular dystrophy. J Pediatr 204:305-313

Publisher's note Springer Nature remains neutral with regard to jurisdictional claims in published maps and institutional affiliations. 